\title{
Euro Currency Trends In The Global Market
}

\author{
C. Pat Obi, (Email: obi@ calumet.purdue.edu), Purdue University Calumet
}

\begin{abstract}
This study presents preliminary evidence on the long-term relationship between the euro and major international financial and non-financial assets. A secular relationship, if it exists, should provide the impetus for the new European currency to not only sustain itself over the long haul but also become a commanding international currency just like the U.S. dollar. Empirical results show that the pricing of crude oil is inversely related to the value of the euro, priced in U.S. dollars. Unit root tests show that series are stationary after first differencing, and cointegrated. However, Granger causality tests reveal that the euro does not Granger-cause crude oil price. Also, there is no reverse causality from oil to euro. Nonetheless, a two-way causality exists between the euro and the U.S. stock market. Contrary to the findings in earlier studies, there is no evidence of causality from the U.S. stock market to leading European financial market series.
\end{abstract}

\section{Background}

his study is an attempt to show how the value of the euro is interlinked with the changing values of crude oil, interest rates, and major global market indexes. The path for achieving this begins with determining whether a relationship exists between crude oil price and the euro. Once relationships have been identified, euro pricing effects are studied in concert with financial market variables. The degree of impact of euro on crude oil is then compared to those coming from either interest rates or stock market values in a vector autoregressive (VAR) framework. Specific relationships are traced on three grounds: (1) which economic variables lead the other in the sense of causality, (2) whether any feedback or bi-directional causality is present, and (3) whether any of the variables are determined contemporaneously.

Crude oil is the representative international commodity in this study against which the intertemporal value of the euro is measured. This commodity is chosen due to its preeminence as the world's largest cash commodity. Crude oil futures contracts began trading on the New York Mercantile Exchange (NYMEX) in 1983 and remains the most traded complex in the commodities market. A great deal of the politics about crude oil is influenced by the production decisions of the 11-member states of the Organization of Petroleum Exporting Countries (OPEC). At the end of 2001, OPEC controlled over 40 percent of crude oil production and almost 80 percent of proved oil reserves. Further, crude oil and allied products command about 40 percent in global market share. ${ }^{1}$ The politics and economic importance of this commodity are widely documented. Equally significant is the wide ranging evidence presented in the literature as to the pervasive influence of crude oil production and pricing on inflation and economic activity. Examples of studies that have addressed these issues include Brown and Yücel (1999), Obi and Malone (1997), Brown et al (1995), and Perron (1989). Therefore, the value of crude oil in the policy initiatives of the United States, European Union, and elsewhere can only be appreciated in terms of its economic significance.

The euro, on the other hand, was formally introduced as a tradable international currency on January 1, 1999. Also on this date, the irrevocable conversion rates between the euro and the eurozone currencies went into effect. Until this date, the European Currency Unit, ECU, was the representative currency index of the financial values of the currencies of the European Union (EU) countries that signed on to the 1992 Maastricht Treaty. ${ }^{2}$ Twelve of the 15 countries of the Union went on to adopt the single currency. In fact, the value of the euro at its inception derived directly from the value of the ECU priced at $\$ 1.183$ per euro.

Readers with comments or questions are encouraged to contact the author via email. 
Value of the euro has risen steadily since the last quarter of 2001, which has brought renewed optimism about the future prospects of the new European currency. Currencies gain in prestige and international presence when they underlie international transactions. Such currencies signify the confidence that the international community has in the stability of the issuing country's political economy. In many cases, it is an acknowledgement of the effectiveness of that country's monetary policies. There is yet another benefit to a country whose currency denominates international assets. It removes the need to hedge against exchange rate risk leaving only asset price fluctuations as the only relevant risk to hedge. Businesses located in other countries must contend with hedging both risk factors in order to immunize their income flows. The U.S. dollar became the international currency of choice after World War II. Before then, the British pound sterling denominated most international transactions.

In general, the value of the euro will rise if foreign inflow of capital in the eurozone rises more than European spending on foreign goods and services. This would happen if the EMU balance of payments is increasingly negative, which would cause euro value to depreciate against say, the dollar. The extent that crude oil price influences euro value can either be viewed as a crowding out effect or a direct impact of EMU balance of payment.

Most previous exchange rate or energy-related studies have not explicitly addressed the role of energy or stock market values in the pricing of a currency. Many of these studies, such as Aggarwal and Park (1994), in stead trace the effects of exchange rate changes on financial market relationships. The role of currency values in influencing economic activity of countries is significant. In addition to maintaining low inflation, economic growth, and high employment, most monetary policy initiatives are also designed to assure favorable currency values. Recent studies dealing with such issues include Laopodis (2001), Swanson (2000), Arize (1997), Ajayi (1996), and Bahmani and Sohrabian (1992). Many of these studies, especially Arshanapalli and Doukas (1993), trace linkages between stock markets, exchange rates, and other macroeconomic variables. More recently, Bley and Madura (2001) find that stock markets are now even more integrated since the inception of the euro, making differences in market structures less significant.

This study considers the potential for the euro to become an influential international currency by tracing linkages between it and major financial market variables. As Figure 1 shows, the steady upsurge in euro value in particular in the first half of 2002 may be evidence that this new currency may yet be a formidable asset in the international monetary market. From a low of almost $\$ 0.80$ in late 2000, it rose up to parity against the U.S. dollar by mid 2002. It is arguable that these recent shifts may be more in response to ongoing problems with the American economy. These include the continuing uncertainties about terrorist attacks on American interests, accounting irregularities by U.S. firms (e.g. Enron, WorldCom, Xerox, and AOL-Time Warner), and the general weakness of the U.S. economy. ${ }^{3}$ It is questionable however as to whether these factors would have a sustained negative impact on the dollar's value in a way that would bring about a preference for the euro in the long haul.

In this study, a multivariate framework is used to investigate the dynamic relations between the euro, measured in terms of the U.S. dollar, and crude oil price. In addition, the linkages between the euro are assessed against stock market and interest rate variables from both the United States and Europe. Empirical results show that an inverse relationship exists between the euro and crude oil price. Granger causality tests reveal that the euro does not Granger-cause the pricing of crude oil. There is no reverse causality from oil to euro either. However a two-way causality exists between the euro and the U.S. stock market.

\section{Data And Methodology}

Along with exchange rate data for the euro, data are also obtained for the following stock indices: S\&P 500 index, FTSE 100 index, DAX index, and Euro Stoxx Broad index. The impact of monetary policy is assessed by the inclusion of two key short-term interest rate variables: the U.S. Federal Funds interest rate and the EU overnight deposit rate. Crude oil price is based on the spot quotes for the benchmark crude, West Texas Intermediate. All data are monthly. Altogether, 99 monthly observations are obtained for each of the eight variables.

Exchange rate data, from the OANDA database, are expressed in direct quotes in U.S. dollars per euro. Federal funds interest rate and EU overnight rate are obtained from the U.S. Federal Reserve Bank and the European 
Central Bank, respectively. Remaining data are retrieved from the Economagic database. Sample period is from January 1994 to March 2002. It is important to point out that because the euro came into force on January 1999, exchange rate data prior to this date were based on the European Currency Unit (ECU). ${ }^{4}$

Data are first converted into natural logarithms and then tested from stationarity. Stationarity tests are carried out in order to determine whether simple VAR models or error correction models are appropriate for examining relationships between the dollar price of euro and the other economic variables. Tests for stationarity using Phillips-Perron (PP) unit root tests are often preferred over Dickey-Fuller (DF) because the PP nonparametric transformation allows for serial correlation and autoregressive heteroscedasticity. In addition, Perron (1989) shows that DF unit root tests tend to be biased toward non-rejection of the hypothesis of a unit root if the time series contains major breaks. Given that the formal launching of the euro on 1/1/1999 and the September 11, 2001 terror attacks in New York occurred during the sample period, it is not unlikely that significant breaks may be present in the time series. Test results of the Augmented Dickey-Fuller (ADF) unit root in this study are the same as the PP test results.

\section{VAR Formulation}

If time series is stationary in levels, it means that it cannot be cointegrated with any of the other series. If the series is stationary, or if the series is nonstationary but not cointegrated, standard VAR estimation is appropriate and Granger causality tests can be conducted. In this circumstance, the restricted bivariate equation for any of the variables becomes:

$$
\mathrm{Y}_{\mathrm{t}}=\alpha+\sum_{i=1}^{p} \beta_{i} Y_{t-i}+\varepsilon_{\mathrm{t}}
$$

where $\alpha$ is the constant term, $Y_{t}$ is a (px1) vector of the variables under study, and $\varepsilon_{t}$ is the disturbance term of dimension (px1) and is iid Gaussian process with zero mean and variance, $\Omega$. The unrestricted VAR model provided by Granger (1969), which can be expressed as a bivariate vector autoregressive (BVAR) model is presented as follows:

$$
\Delta \mathrm{Y}_{\mathrm{t}} \quad=\alpha+\Sigma \beta_{\mathrm{i}} \Delta \mathrm{Y}_{\mathrm{t}-\mathrm{i}}+\Sigma \theta_{\mathrm{i}} \Delta \mathrm{X}_{\mathrm{t}-\mathrm{i}}+\varepsilon_{\mathrm{t}}
$$

where $\Delta$ is the first difference operator and $\mathrm{X}$ is a vector representing other variables in the system. If the $\theta$ coefficients in Equation (2) are significant, then X "granger-causes" Y. To test for reverse causality, the X's and Y's are reversed. Contemporaneous determination can be tested by including the current value of $\mathrm{X}$. When the contemporaneous term is included, we seek to determine whether relationships can be determined simultaneously as opposed to any of the variables leading the other.

If, on the other hand the variables are nonstationary and integrated of the same order, cointegration tests are performed. If time series are cointegrated, they have a long-term relationship, which means they will tend to move together by and large. This characteristic of cointegrated series makes the VAR model, which deals only with shortterm changes, inappropriate because long-term relationship information is often lost.

If the series are cointegrated, then an error correction model (ECM) of the following form is appropriate:

$$
\Delta \mathrm{Y}_{\mathrm{t}}=\alpha_{0}+\alpha_{1}\left(\mathrm{Y}_{\mathrm{t}-1}-\mathrm{dX}_{\mathrm{t}-1}\right)+\sum_{i=1}^{p} \mathrm{c}_{\mathrm{i}} \Delta Y_{t-i}+\sum_{i=1}^{q} \mathrm{~d}_{\mathrm{i}} \Delta X_{t-i}+v_{\mathrm{t}}
$$

where $\mathrm{p}$ and $\mathrm{q}$ are lag terms sufficient to make the error term, $v$, white noise. The coefficient of the error correction term, $\alpha_{1}$, measures the single period response of $\mathrm{Y}$ to departures from equilibrium. If $\mathrm{Y}$ and $\mathrm{X}$ are cointegrated, causality must exist in at least one direction. 


\section{Linear Formulations}

Preliminary investigation into the relationships between crude oil price and the euro is carried out to show whether a simple regression relationship exists between these two variables. By this construct, one is able to trace the unique role of the euro currency in the pricing of crude oil. The initial simple linear model specifies oil price and exchange rate as the dependent and explanatory variables, respectively.

$$
\mathrm{OP}_{\mathrm{t}}=\alpha+\beta_{\mathrm{i}} \mathrm{ER}_{\mathrm{t}-\mathrm{i}}+\varepsilon_{\mathrm{t}}
$$

where ER is euro exchange rate and OP is oil price. Equation (4) looks only at the euro effect. The alternative formulation depicted in Equation (5), below, adds each of the remaining independent variables in order to assess which model best explains intertemporal variations in crude oil price.

$$
\mathrm{OP}_{\mathrm{t}}=\alpha+\beta_{\mathrm{i}} \mathrm{ER}_{\mathrm{t}-\mathrm{i}}+\lambda_{\mathrm{i}} \mathrm{X}_{\mathrm{t}-\mathrm{i}}+\varepsilon_{\mathrm{t}}
$$

where $\mathrm{X}$ refers to an interest rate variable or a stock market index. Thus, Equation (5) looks at the euro effect in conjunction with a stock market or interest rate variable.

\section{Granger Causality Tests}

Regressions alone do not necessarily imply causality except to the extent that they can help identify the existence of a relationship between variables. The Granger (1969) method seeks to determine whether X causes Y, and how much of the current $\mathrm{Y}$ can be explained by past values of $\mathrm{Y}$. In addition, it determines whether adding lagged values of $\mathrm{X}$ to the model can improve the explanation. In effect, $\mathrm{X}$ is said to Granger-cause $\mathrm{Y}$ if $\mathrm{X}$ helps in the prediction of $Y$, or equivalently, if the coefficients on the lagged $X$ 's are statistically significant. Sometimes, a twoway causality is established in the sense that X Granger-causes $\mathrm{Y}$ and Y Granger-causes $\mathrm{X}$. It is instructive to point out that Granger causality does not by itself measure causality in the common sense of the term. Rather, it measures precedence and information content in the variables.

The number of lags used in Granger causality tests is important. If the maximum depth of information must be extracted, then it is better to use more rather than fewer lags, since the theory is rooted on the relevance of all historical information. It is generally helpful to choose a lag length that conforms to reasonable beliefs about the longest time over which one variable may help predict the other. By expanding Equation (1), a causality model with 1 number of lags may be represented as:

$$
\mathrm{Y}_{\mathrm{t}}=\alpha_{0}+\alpha_{1} \mathrm{Y}_{\mathrm{t}-1}+\ldots+\alpha_{\mathrm{l}} \mathrm{Y}_{\mathrm{t}-\mathrm{l}}+\beta_{0}+\beta_{1} \mathrm{X}_{\mathrm{t}-1}+\ldots+\beta_{\mathrm{l}} \mathrm{X}_{\mathrm{t}-\mathrm{l}}+\varepsilon_{\mathrm{t}}
$$

or

$$
X_{t}=\alpha_{0}+\alpha_{1} X_{t-1}+\ldots+\alpha_{1} X_{t-1}+\beta_{0}+\beta_{1} Y_{t-1}+\ldots+\beta_{t} Y_{t-1}+\varepsilon_{t}
$$

Equation (6) is expressed without a contemporaneous term. If a contemporaneous term is added, the model in compact form becomes:

$$
\mathrm{Y}_{\mathrm{t}}=\alpha_{0}+\Sigma \lambda_{\mathrm{i}} \mathrm{Y}_{\mathrm{t}-\mathrm{i}}+\delta \mathrm{X}_{\mathrm{t}}+\Sigma \beta_{\mathrm{i}} \mathrm{X}_{\mathrm{t}-\mathrm{i}}+\varepsilon_{\mathrm{t}}
$$

where $X_{t}$ satisfies causality impact in the current time period. Altogether, a maximum of four lags is used in this study.

\section{Empirical Results}


Table 1 shows regression results for Equations 4 and 5. The initial inquiry is designed to show the degree of impact on oil pricing by the new European currency. Subsequently, each of the specified variables is added to the model to determine how much additional information, if any, is contributed. Results show that a significant regression relationship exists between oil price and the euro. The correlation matrix in Table 2 shows that this relationship is inverse in that an increase in euro value is associated with a decline in the price of crude oil. No more than about 30 percent of the total volatility in crude oil price is explained by variations in the price of euro. This would indicate that there are other variables impacting the price of oil as demonstrated in Ayadi et al (2000). Unfortunately, with the exception of the Federal funds interest rate, the fit of the model was not significantly improved by the addition of the other explanatory variables.

The correlation data in Table 2 shows that, with the exception of the two interest rate variables, the euro is negatively correlated with each of the time series. Since exchange rate is measured in direct U.S. dollar terms (\$/euro), it means for example, that increases in crude oil price are typically associated with a decline in the value of the euro because it would require fewer dollars to buy one euro. The rest of the matrix shows that the stock indices are highly and positively correlated with each other. While these indices are in general negatively correlated with the interest rate variables, they all appear to be much more highly correlated with the European interest rate than with U.S. interest rate. Perhaps this asymmetry in correlations signifies greater uncertainty in the monetary policy effects of an economic union whose member countries have far greater cultural, economic, and political differences than there are in the United States.

Simple regressions and correlations do not necessarily reveal long-term trends in relationships or causality among variables. The vector autoregressive (VAR) model provides a path to make this important determination. The first step to this is to determine whether series are stationary by way of a unit root test. Unit root test results are summarized in Table 3. In their levels, results show that none of the variables is stationary; they all contain a unit root. However, in their first differences, they do not contain unit root and therefore are all unambiguously stationary. In other words, each series is integrated of the order I(1). Test results show that these financial time series are largely cointegrated. The hypothesis of at most 5 cointegrating vectors is rejected at the 0.05 level of significance. Results of the Johansen (1991) cointegration tests are presented in Table 4.

Granger causality test results, without contemporaneous effects, are reported in Table 5. Because the inclusion of lagged dependent variables as independent variables in the model can cause biased $\mathrm{F}$ results, Wald test statistics are computed and reported in the table. A significant Wald statistic indicates Granger causality from one series to the other.

The data rows of results report direct causality from each of the time series. When Causality from Euro is considered, the Wald statistics reveal no significant Granger causality from euro to crude oil price. There is also no reverse causality from crude oil price to euro. These results show that while the two variables may be cointegrated, there is no evidence that causality exists between them.

It is important to note that causality from euro to the two U.S. variables, S\&P 500 and Federal funds interest rate, is statistically significant at the 5 percent and 1 percent, respectively. There is a reverse causality from S\&P to the euro but none from Fed funds. It is perhaps interesting to note that, with the exception of oil price and E.U. overnight rate, each of the other variables Granger-causes the United States federal funds interest rate. There is no notable reverse causality from federal funds rate except with respect to the EU overnight rate.

\section{Conclusions}

This study presents preliminary results about relationships between the new European currency, the euro, and leading macroeconomic variables from both the United States and the European Union. As the world's largest cash commodity, crude oil is used as a target variable to determine the extent of impact the pricing of the euro has on this important global asset. A significant relationship together with evidence of causality could signal the ability of the euro to become a commanding international currency. 
While regression results show a significant relationship between oil price and euro (with euro as the explanatory variable), there is no reason to believe that the euro's impact is a commanding one. Further, the addition of the remaining variables to the model contributed only marginally in explaining intertemporal variations in crude oil pricing. There is evidence however that crude oil price is inversely related to the value of the euro, an outcome that should discourage oil producing countries and dealers from a euro preference.

Long-term relationships between oil price and the other variables are traced in a vector autoregressive framework. Unit root tests confirm that all the time series are stationary in their first differences. With this, a path for cointegration tests and error correction formulation is established. Johansen cointegration test results show that the series are cointegrated. More importantly, Granger causality test results show that there is no evidence of causality between the euro and oil price, although causality exists from the euro to both the S\&P index and the Fed funds interest rate. It is interesting to note that causality does not exist from the euro to any of the European economic variables. Also, there is no reverse causality from oil price to any of the other variables.

Finally, it is noteworthy that there is no causality from the U.S. economy (as proxied by the S\&P 500 index) to crude oil price, the British economy (as proxied by the Financial Times index), and E.U. monetary policy initiatives (as proxied by the E.U. overnight interest rate). While lack of causality from the U.S. market to foreign markets is unusual, the results of this study agree in some ways with the findings of Swanson (2000) and Aggarwal and Park (1994) in that they find that the U.S. market did not always lead other national equity markets.

Two outcomes of this study are particularly striking. The first is that little evidence is presented to believe that a substantive linkage exists between the euro and important international assets such as crude oil. The second is that the one-directional causality from U.S. monetary policy initiatives, as proxied by the federal funds interest rate, to the E.U. overnight interest rate would appear to add to the widely held notion that the European Central Bank largely tows the path of the Federal Reserve's interest rate policy.

\section{Footnotes}

1. Reference: BP Statistical Review of World Energy, June 2002

2. Britain, Denmark, and Sweden are the three EU countries that chose not to be part of the Economic and Monetary Union (EMU) at the current time.

3. The following issues of the Wall Street Journal contain stories about financial market response to U.S. economic uncertainties: Monday June 24, 2002 entitled "Corporate Profit Fears Put Damper on U.S. Stocks," and Thursday June 27, 2002 entitled "Fed Holds Steady Despite Anxieties Among Investors."

4. The ECU was a basket of the currencies of the countries that now make up the European Economic and Monetary Union. The value of the euro on January 1, 1999 was then defined as the value of the ECU on that date. As a result, the ECU ceased to exits effective on that date.

\section{References}

1. Aggarwal, Raj, and Young S. Park (1994). "The Relationships between Daily U.S. and Japanese Equity Prices: Evidence from Spot versus Futures Markets," Journal of Banking and Finance, Vol. 18, pp. 757-773.

2. Ayadi, O.F., Amitava Chatterjee, and C.P. Obi (2000). "A Vector Autoregressive Analysis of an Oil Dependent Emerging Economy,” OPEC Review, Vol. XXIV, pp. 329-349.

3. Ajayi, Richard A. and Mbodja Mougoue (1996). "On the Dynamic Relation between Stock Prices and Exchange Rates,” Journal of Financial Research, Vol. 19, pp. 193-207.

4. Arize, A.C. (1997). "Foreign Trade and Exchange Rate Risk in the G-7 Countries: Cointegration and Error Correction Models," Review of Financial Economics, Volume 6, Number 1, pp. 95-112.

5. Arshanapalli, Bala, and John Doukas (1993). "International Stock Market Linkages: Evidence from Pre- and Post-October 1987 Period," Journal of Banking and Finance, Vol. 27, 193-208.

6. Bahmani-Oskooee, Mohsen and Ahmad Sohrabian (1992). "Stock Prices and the Effective Exchange Rate of the Dollar, Applied Economics, Vol. 24, 459-464. 
7. Bley, Jorge, and Jeff Madura (2001). "Impact of the Euro on European Portfolio Diversification," Global Business and Finance Review, Fall, pp. 17-29.

8. Brown, S.P.A., D.B. Oppendahl, and M.K. Yücel (1995). “Oil Prices and Inflation,” Federal Reserve Bank of Dallas, Working Paper 95-10.

9. Brown, S.P.A. and M.K. Yücel (1999). "Oil Prices and U.S. Aggregate Economic Activity: A Question of Neutrality," Federal Reserve Bank of Dallas Economic and Financial Review, Second Quarter, pp. 16-23.

10. Dickey, D.A. and W.A. Fuller (1981). "Likelihood Ratio Statistics for Autoregressive Time Series with a Unit Root," Journal of the American Statistical Association, Vol. 74, July, pp. 1057-72.

11. Engle, R. and C. Granger (1987). "Cointegration and Error Correction: Representation, Estimation, and Testing," Econometrica, Volume 55, pp. 251-276

12. Granger, C.W.J. (1969). "Investigating Causal Relations by Econometric Models and Cross-Spectral Methods," Econometrica, Volume 37, pp. 424-438.

13. Laopodis, Nikiforos T. (2001). "Does Exchange Rate Volatility Affect Trade? Evidence from Several European Countries." Global Business and Finance Review, Volume 6, Number 1, pp. 13-22.

14. Johansen, S. (1991). "Estimation and Hypothesis Testing of Cointegration Vectors in Gaussian Vector Autoregressive Models," Econometrica, November, pp. 1551-1580.

15. Johansen, S. (1988). "Statistical Analysis of Cointegrating Vectors," Journal of Economic Dynamics and Control, June-September, pp. 231-254.

16. Obi, C. Pat and R. Phil Malone (1997). "Crude Oil Futures and Bond Portfolio Management: Opportunities for Intermarket Cross Hedge," Journal of Energy Finance and Development, Vol. 2, No. 2, pp. 197-211.

17. Phillips, P. and P. Perron (1988). "Testing for a Unit Root in Time Series Regression," Biometrica, Vol. 75, pp. 333-346.

18. Perron, Pierre (1989). "The Great Crash, the Oil Price Shock and the Unit Root Hypothesis," Econometrica, Vol. 57, pp. 1361-1401.

19. Rouwenhorst, K. (1999). "European Equity Markets and the EMU," Financial Analysts Journal, May/June, pp. 57-64.

20. Swanson, Peggy E. (2000). "A Preliminary Investigation of the Effects of Exchange rates on national Equity Market Relationships," Global Business and Finance Review, Fall, 13-19.

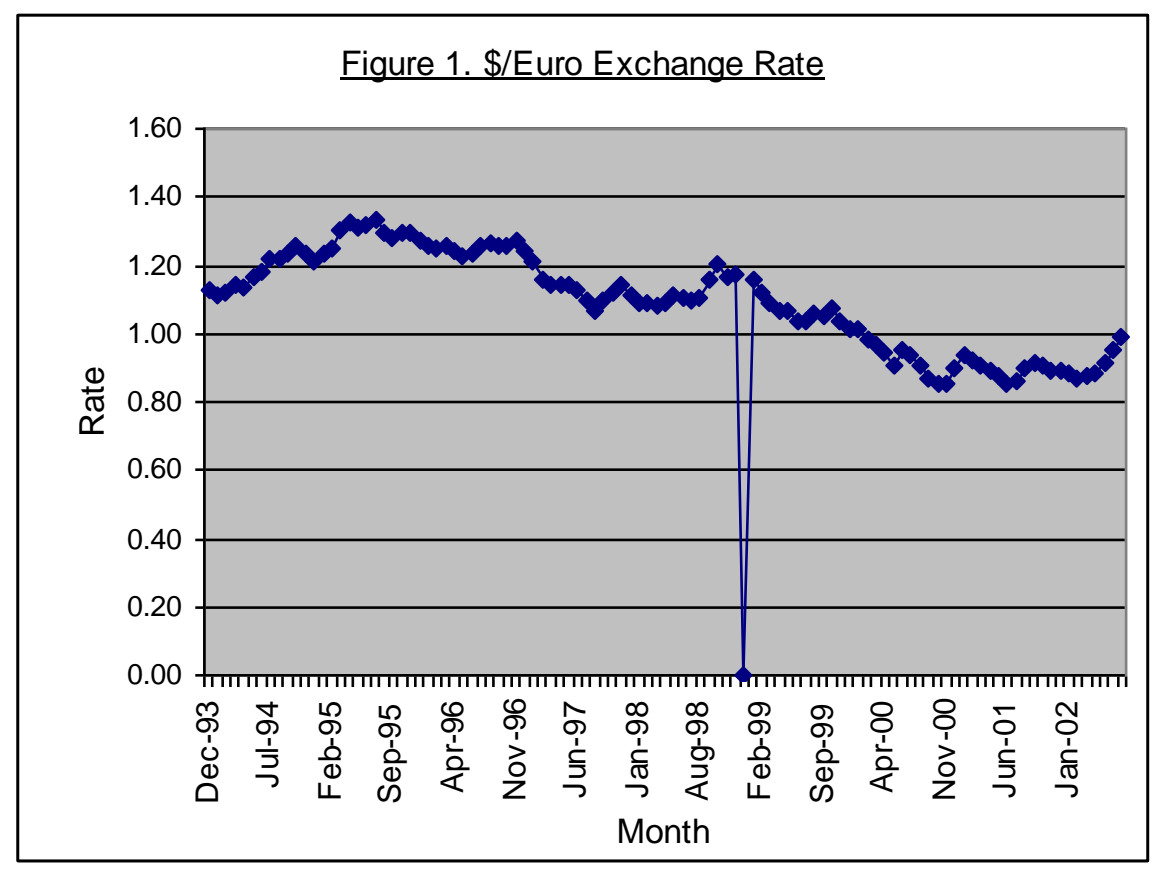


January 1, 1999 marked the official launch of the euro.

Table 1

Direct Euro Effects on Oil Price; Other Series Paired with Euro

\begin{tabular}{|l|c|c|}
\hline \multicolumn{2}{|c|}{$\mathrm{OP}_{\mathrm{t}}=\alpha+\beta_{\mathrm{i}} \mathrm{ER}_{\mathrm{t}-\mathrm{i}}+\lambda_{\mathrm{i}} \mathrm{X}_{\mathrm{t}-\mathrm{i}}+\varepsilon_{\mathrm{t}}$} \\
\hline \multicolumn{1}{|c|}{ Independent Variable(s) } & R-square & F statistic \\
\hline Euro & 0.3027 & $42.11^{* *}$ \\
\hline Euro; Euro Stoxx & 0.3146 & $22.03^{* *}$ \\
\hline Euro; DAX & 0.3164 & $22.21^{* *}$ \\
\hline Euro; FTSE & 0.3103 & $23.05^{* *}$ \\
\hline Euro; S\&P & 0.3082 & $21.39^{* *}$ \\
\hline Euro; Fed Funds & 0.4242 & $35.36^{* *}$ \\
\hline Euro; EU rate & 0.3496 & $25.80^{* *}$ \\
\hline
\end{tabular}

$*$ and ** denote rejection of the null hypothesis at the 0.05 and 0.01 levels, respectively.

$\mathrm{OP}=$ Oil price

$\mathrm{ER}=$ Euro exchange rate (in US \$ term)

$\mathrm{X}=$ Euro stoxx index; DAX index; FTSE 100 index; S\&P 500 index; Fed funds rate; EU overnight rate

Table 2

Correlation Half-Matrix of Time Series

\begin{tabular}{|c|c|c|c|c|c|c|c|c|}
\hline Time Series & Euro & Oil & Euro Stoxx & DAX & FTSE 100 & S\&P 500 & Fed Funds & EU Ovnt. \\
\hline Euro & 1 & & & & & & & \\
\hline Oil & -0.5502 & 1 & & & & & & \\
\hline Euro Stoxx & -0.8536 & 0.4128 & 1 & & & & & \\
\hline DAX & -0.8246 & 0.3875 & 0.9926 & 1 & & & & \\
\hline FTSE & -0.7256 & 0.2979 & 0.9603 & 0.9726 & 1 & & & \\
\hline S\&P500 & -0.7667 & 0.3741 & 0.9680 & 0.9761 & 0.9864 & 1 & & \\
\hline Fed Funds & 0.3529 & 0.1320 & -0.0373 & -0.0112 & 0.0494 & -0.0085 & 1 & \\
\hline EU Ovnt. & 0.3981 & -0.0203 & -0.6799 & -0.7016 & -0.7830 & -0.7807 & 0.1268 & 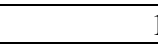 \\
\hline
\end{tabular}

Table 3

Unit Root Test Results (lag length = 0)

\begin{tabular}{|c|c|c|c|c|}
\hline \multirow[t]{2}{*}{ Variable } & \multicolumn{2}{|c|}{ Level Data } & \multicolumn{2}{|c|}{ Differenced Data } \\
\hline & ADF & P-value & ADF & P-value \\
\hline Euro & -0.5811 & 0.4632 & -7.3337 & 0.0000 \\
\hline Crude oil & 0.5133 & 0.8248 & -8.2819 & 0.0000 \\
\hline DAX & 1.3902 & 0.9582 & -9.9618 & 0.0000 \\
\hline FTSE 100 & 1.0347 & 0.9203 & -9.6855 & 0.0000 \\
\hline Euro stoxx & 1.7229 & 0.9790 & -7.1188 & 0.0000 \\
\hline S\&P 500 & 2.2295 & 0.9937 & -9.5464 & 0.0000 \\
\hline Fed Funds rate & -0.7264 & 0.3995 & -4.0903 & 0.0001 \\
\hline EU overnight rate & -1.6168 & 0.0996 & -9.5796 & 0.0000 \\
\hline
\end{tabular}

$\mathrm{ADF}=$ Augmented Dickey-Fuller

Critical values for the ADF statistics are -2.59 and -1.94 at the $1 \%$ and $5 \%$ levels, respectively. Differenced data test statistics are all significant at both levels.

Table 4

Johansen Cointegration Test 


\begin{tabular}{|c|c|c|c|c|c|}
\hline Hypothesis & Trace Statistic & $\begin{array}{c}\text { Critical Value } \\
\text { for } \alpha=0.05\end{array}$ & Hypothesis & $\begin{array}{c}\text { Max-Eigen } \\
\text { Statistic }\end{array}$ & $\begin{array}{c}\text { Critical Value } \\
\text { for } \alpha=0.05\end{array}$ \\
\hline $\mathrm{r}=0$ & $264.35 * *$ & 141.20 & $r=0$ & $89.22 * *$ & 47.99 \\
\hline $\mathrm{r} \leq 1$ & $175.13 * *$ & 109.99 & $r=1$ & $49.76 * *$ & 41.51 \\
\hline $\mathrm{r} \leq 2$ & $125.37 * *$ & 82.49 & $r=2$ & $42.21 * *$ & 36.36 \\
\hline $\mathrm{r} \leq 3$ & $83.16 * *$ & 59.46 & $r=3$ & $30.81 *$ & 30.04 \\
\hline $\mathrm{r} \leq 4$ & $52.35 * *$ & 39.89 & $r=4$ & $24.78 *$ & 23.80 \\
\hline $\mathrm{r} \leq 5$ & $27.58 *$ & 24.31 & $r=5$ & $19.13 *$ & 17.89 \\
\hline $\mathrm{r} \leq 6$ & 8.44. & 12.53 & $r=6$ & 7.70 & 11.44 \\
\hline $\mathrm{r} \leq 7$ & 0.74 & 3.84 & $r=7$ & 0.74 . & 3.84 \\
\hline
\end{tabular}

$*$ and ** denote rejection of the hypothesis at the 0.05 and 0.01 levels, respectively. This suggests series are cointegrated with at most 5 cointegrating vectors.

$r=$ number of cointegrating vectors

Series: euro, oil price, Euro stoxx, DAX, FTSE 100, S\&P500, Fed funds, EU overnight rate

Table 5

Granger Causality Wald Statistics (Without Contemporaneous Term)

\begin{tabular}{|c|c|c|c|c|c|c|c|c|}
\hline \multicolumn{9}{|c|}{$Y_{t}=\alpha_{0}+\alpha_{1} Y_{t-1}+\ldots+\alpha_{1} Y_{t-1}+\beta_{0}+\beta_{1} X_{t-1}+\ldots+\beta_{1} X_{t-1}+\varepsilon_{t}$} \\
\hline & \multicolumn{8}{|c|}{ Causality to: } \\
\hline & Oil & Euro & S\&P & FTSE & DAX & Stoxx & F-Funds & EU Ovnt \\
\hline \multicolumn{9}{|c|}{ Causality from: } \\
\hline Crude Oil & & 0.723 & 1.444 & 0.796 & 0.541 & 2.269 & 0.464 & 1.064 \\
\hline Euro & 2.119 & & $3.374 *$ & 2.160 & 1.092 & 1.353 & $3.840 * *$ & 0.897 \\
\hline S\&P 500 & 1.983 & $5.102 * *$ & & 0.586 & $2.774 *$ & $7.357 * *$ & $5.812 * *$ & 0.820 \\
\hline FTSE 100 & 1.707 & $3.057 *$ & 0.381 & & $3.759 * *$ & $8.299 * *$ & $3.236^{*}$ & 1.555 \\
\hline DAX index & 2.323 & $4.554 * *$ & 1.501 & 1.622 & & $7.327 * *$ & $7.885 * *$ & $4.020 * *$ \\
\hline Euro Stoxx & $4.631 * *$ & 2.022 & 2.077 & 2.015 & 1.474 & & $6.021 * *$ & 2.066 \\
\hline Fed Funds & 2.363 & 1.298 & 0.346 & 0.461 & 0.623 & 1.838 & & $3.149 *$ \\
\hline EU Ovnt & 0.612 & 1.402 & 2.043 & 1.821 & $4.010 * *$ & $3.612 * *$ & 0.428 & \\
\hline
\end{tabular}

$\mathrm{H}_{0}$ : $\mathrm{X}$ does not Granger-cause Y (i.e. there is no Granger causality)

$*$ and $* *$ denote rejection of the null hypothesis at the 0.05 and 0.01 levels, respectively.

Notes 